Exp Brain Res (1989) 74: 563-572

\title{
Flash evoked potentials in the ectostriatum of the zebra finch: a current source-density analysis
}

\author{
J. Engelage* and H.-J. Bischof \\ Fakultät für Biologie, Lehrstuhl für Verhaltensphysiologie der Universität Bielefeld, Postfach 8640, D-4800 Bielefeld 1, \\ Federal Republic of Germany
}

Summary. Recent research has demonstrated that ipsilaterally visually evoked potentials (VEPs) can be measured within the ectostriatum, the telencephalic target area of the tectofugal visual pathway in birds. In this paper we systematically measured contra- and ipsilateral VEPs within the ectostriatal complex to obtain more detailed information on the processing of contra- and ipsilateral stimuli. The similarity of neighbouring VEPs at equal depth and a comparison of a one dimensional and a three dimensional analysis of current source-densities (CSDs) for identical coordinates suggested that a one dimensional current source-density analysis might be applicable. The one dimensional current source-density analysis demonstrated largely corresponding patterns in the sink source sequences of the current source-density depth profiles for the contra- and ipsilateral stimulus responses. The occurrence of a large sink in the centre of the ectostriatal core, together with the results of multiunit recordings, shows that the ectostriatal core is the location of the generators for both the contra- and the ipsilaterally evoked responses. The occurrence of macroscopic sinks and sources and the fact that VEPs can be recorded from the ectostriatum shows that there is a higher degree of order in the ectostriatum than has been previously demonstrated by anatomical methods. The time coincidence between the maximum spike rate of multiunit responses, the negative peak of the evoked potential, and the large central sink demonstrates that the influence of ipsi- as well as of contralateral stimuli is predominantly excitatory.

Key words: Zebra finch - Visually evoked potentials - Ectostriatum - Ipsi- and contralateral stimulus responses - Current source-density analysis

\footnotetext{
* Present address: University of Oxford, Laboratory of Physiology, Parks Road, Oxford OX1 3PT, U.K.

Offprint requests to: $\mathrm{H}$.-J. Bischof (address see above)
}

\section{Introduction}

In birds with lateral eyes, the tectofugal visual pathway is much more prominent than the thalamofugal pathway, which in turn is more developed in birds with frontal eyes like most nocturnal raptors (Ebbeson 1970; Pettigrew 1977). Therefore, it is likely that in birds with lateral eyes, like the zebra finch, the tectofugal system has a major importance for the processing of visual information.

In contrast to rather detailed information on the optic tectum (Jassik-Gerschenfeld and Guichard 1972; Mori 1973; Holden 1968a, b; Hardy et al. 1984), the knowledge about visual processing in higher stations of this pathway, the nucleus rotundus and the ectostriatum, is sparse.

Early electrophysiological evidence for the processing of visual information in the nucleus rotundus and the ectostriatum was provided by evoked potential recordings with electrical stimulation of the ipsilateral tectum opticum and nucleus rotundus (Revzin and Karten 1966). These results were confirmed with flash evoked potentials by Parker and Delius (1972). The neurons of the nucleus rotundus have large receptive fields and respond best to fast moving stimuli (Maxwell and Granda 1979). Moreover, Yazulla and Granda (1973, Granda and Yazulla 1971) demonstrated colour coding properties of rotundal neurons. Ectostriatal neurons resemble the receptive field properties of rotundal neurons (Revzin 1970; Kimberly et al. 1971).

In general, the tectofugal pathway has been seen as to be exclusively driven by the contralateral eye. However, studies from our laboratory revealed that a strong influence from the ipsilateral eye can be detected electrophysiologically in the telencephalic target area of this pathway, the ectostriatum (Engelage and Bischof 1988). This demonstrates that the interhemispheric connections between the tectofugal 
systems of either side are of more importance than had been previously believed (Benowitz and Karten 1976; Hunt and Künzle 1976; Robert and Cuenod 1969a, b; Hardy et al. 1984). The aim of this study was to examine in more detail the ectostriatal responses to ipsi- and contralateral stimuli. In particular, we were interested in the location of the sinks and sources generating the ectostriatal VEPs, and in an evaluation of functional subdivisions of this nucleus. We therefore applied a current sourcedensity analysis to the ectostriatum. In mammals this method has become a widely accepted and common tool (for review see: Mitzdorf 1985), whereas in birds it seems to be limited to one study in the tectum opticum (Stone and Freeman 1971). In contrast to VEPs the sinks and sources revealed by this method are spatially localized phenomena (e.g. Mitzdorf 1985). Therefore, the current source-density method leads to a much greater spatial resolution of these events and in principle the anatomical aspect of the current source-densities can be used for a functional identification of structures, or even of subdivisions of structures (Müller-Preuß and Mitzdorf 1984; Mitzdorf 1985,1987$)$. In contrast to single unit data, the current source densities predominantly show sites of excitatory synaptic interactions rather than locations of cell somata and, like intracellular recordings, they disclose even subthreshold synaptic events (Mitzdorf 1987). Therefore, this technique should be a useful tool for a closer examination of the function of the ectostriatum. In fact, our experiments reveal that a one dimensional CSD analysis is applicable to the ectostriatum of birds, and that this brain structure is of higher anatomical order than the available evidence suggests.

\section{Material and methods}

The experiments were performed on 20 adult male and female zebra finches obtained from the institute's stock.

\section{Preparation, stimulation and evoked potential recording}

The birds were anesthetized once with an injection of $0.1 \mathrm{ml}$ urethane $(20 \% \mathrm{w} / \mathrm{v})$ and, after about half an hour, mounted in a specially designed stereotaxic headholder (Bischof 1981). Evoked potentials were recorded with glass micropipettes filled with alcian blue in $3 \mathrm{M} \mathrm{NaCl}(5-15 \mathrm{M} \Omega$ ). The stereotaxic coordinates for the electrode positions were derived from an atlas of the zebra finch brain (H.J. Bischof and B.N. Nixdorf, unpublished). In the experiments concerned with the spatial distribution of VEPs in the ectostriatum the recording sites were verified histologically. Visual stimuli were provided by a stroboscope. Flashes were directed to one or both eyes by a fiber optics system. Contra-, ipsi- and bilateral stimuli were selected by opening and closing shutters between the stroboscope and the fiber optics system. The terms ipsilateral and contralateral refer to the position of the recording electrode. Controls were made by closing the shutters in the fiber optics system or, in some cases, by removing the fiber optics system from the eyes. This excluded the contribution of acoustically evoked responses and electrical artifacts which may contaminate the visually evoked potentials (VEPs).

Signals were averaged 64 times by a Nicolet Signal Averager. The interstimulus time interval was five seconds. Storing and processing of the data was accomplished by a HP- 86 microcomputer. This device also triggered the stimuli and controlled the experimental procedure. Amplitudes and peak latencies were estimated with the aid of a minimum-maximum routine of the microcomputer. In addition, detailed information on amplitudes and latencies was obtained by processing the evoked potential plots on a graphics tablet.

\section{CSD analysis}

The extracellular field potential $\Phi$ is related to the active and passive transmembrane currents of cell assemblies of activated neurons by the Poisson equation:

$$
\overrightarrow{\mathrm{v}}^{*} \sigma * \overrightarrow{\mathrm{v}} \Phi=-\mathrm{I}_{\mathrm{m}}
$$

(Freeman and Nicholson 1975; Freemann and Stone 1969; Mitzdorf and Singer 1977; Nicholson and Freeman 1975).

Since no striking anatomical subdivisions can be detected within the ectostriatal complex it is treated as a homogenous structure. It can be assumed that the conductivity tensor $\sigma$ is equal throughout the entire ectostriatum. In optimally orientated rectangular cartesian coordinates, the current source density $I_{m}$ is then given by the second spatial derivative:

$\sigma(x) \frac{\delta^{2} \Phi(\mathrm{x}, \mathrm{t})}{\delta \mathrm{x}^{2}}+\sigma(\mathrm{y}) \frac{\delta^{2} \Phi(\mathrm{y}, \mathrm{t})}{\delta \mathrm{y}^{2}}+\delta(\mathrm{z}) \frac{\delta^{2} \Phi(\mathrm{z}, \mathrm{t})}{\delta \mathrm{z}^{2}}=-\mathrm{I}_{\mathrm{m}}(\mathrm{x}, \mathrm{y}, \mathrm{z}, \mathrm{t})$

If translational symmetry in two dimensions can be assumed in the ectostriatal complex, a one dimensional current source-density analysis can be applied (Nicholson and Freeman 1975). Arguments justifying this assumption are given in the results and the discussion (see below). Equation (2) is then reduced to:

$\sigma(\mathrm{z}) \frac{\delta^{2} \Phi(\mathrm{z}, \mathrm{t})}{\delta \mathrm{z}^{2}}=-\mathrm{I}_{\mathrm{m}}(\mathrm{z}, \mathrm{t})$

The current source-densities were actually calculated with a finite difference formula according to Mitzdorf and Singer (1977).

$-\mathrm{I}_{\mathrm{m}}(\mathrm{x}, \mathrm{t})=\frac{\delta^{2} \Phi(\mathrm{x})}{\delta \mathrm{x}^{2}} \approx \frac{\Phi(\mathrm{x}+\mathrm{n} \Delta \mathrm{h})-2 \Phi(\mathrm{x})+\Phi(\mathrm{x}-\mathrm{n} \Delta \mathrm{h})}{(\mathrm{n} \Delta \mathrm{h})^{2}}$

\section{Results}

\section{Evoked potentials}

In two birds we measured the spatial distribution of contra- and ipsilateral flash evoked responses within the ectostriatal complex. In each bird, using a single electrode, we recorded VEPs in nine tracks with five recording points each (stepwidth $250 \mu \mathrm{m}$, see Figs. 1, 2). The temporal succession of the tracks was chosen randomly. The recording coordinates covered the whole ectostriatal complex. After we had finished the recordings of ipsilateral VEPs in the second bird, we made additional recordings of VEPs to contra- and 


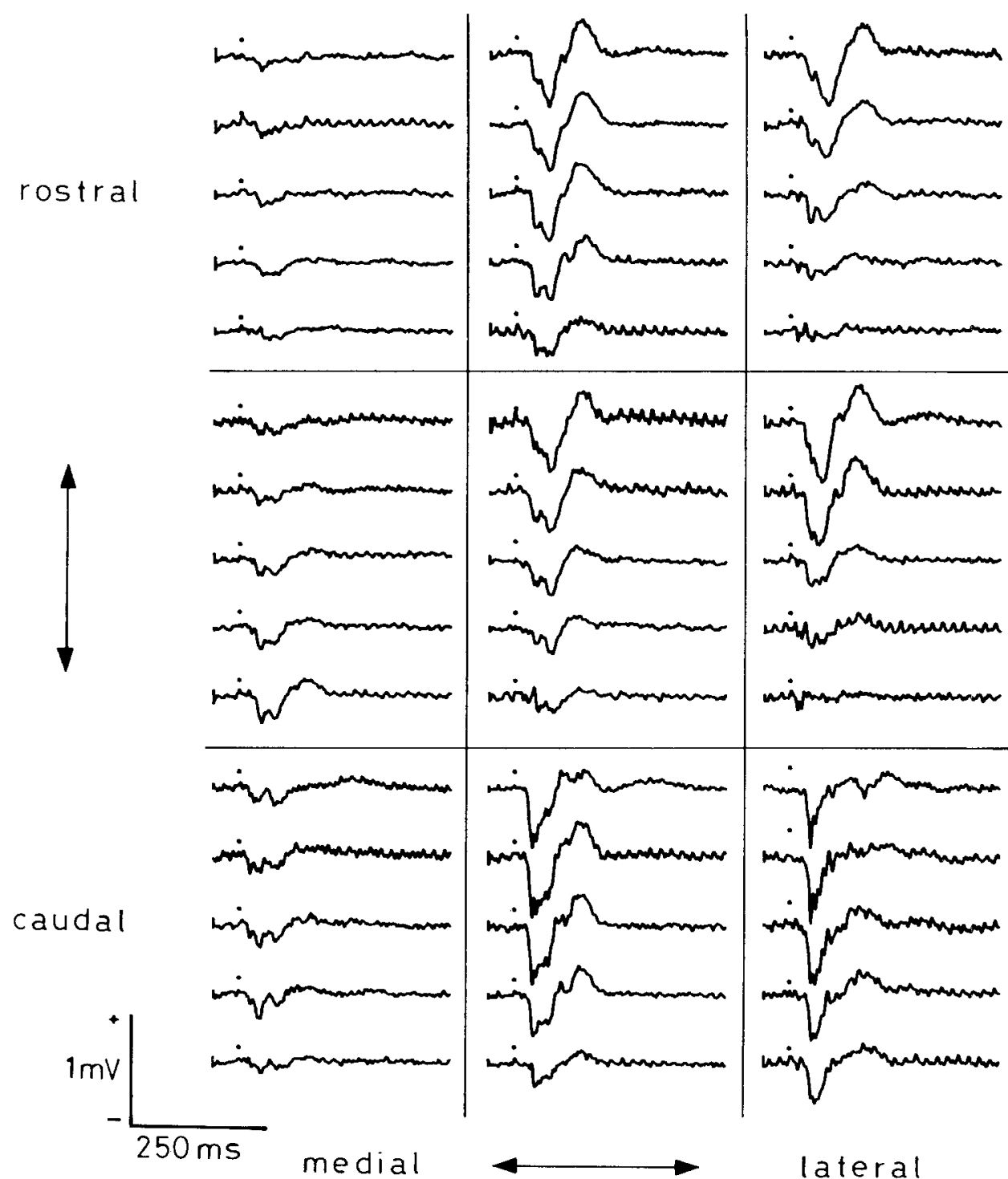

Fig. 1. Spatial distribution of contralaterally evoked responses in the ectostriatum. Lateral spacing between electrode tracks is $750 \mu \mathrm{m}$. Frontal spacing is $500 \mu \mathrm{m}$, depth spacing (step width) is $250 \mu \mathrm{m}$. The minimal and maximal recording depths have been adjusted to orientation of the ectostriatum within the telencephalon. Average $64 \times$, bin width $500 \mu \mathrm{s}$, stimulus at $50 \mathrm{~ms}$ marked by small dots. Note the similarity of the potentials at equal depth in the lateral two columns ipsilateral stimulation in a central location of the ectostriatum. These recordings confirmed the reliability of the amplitude difference between contraand ipsilateral VEPs and the reproducability of VEPs of these recordings even in different birds.

With contralateral stimulation (Fig. 1) we recorded a relatively large negative-positive wave. The negative wave at rostral and intermediate levels consisted of two clearly distinguishable peaks, with latencies of about $40 \mathrm{~ms}$ for the first peak and about $65 \mathrm{~ms}$ for the second and larger peak. For the positive wave we measured peak latencies around $120 \mathrm{~ms}$. The amplitudes of the negative wave ranged from $0.1 \mathrm{mV}$ at the medial border of the ectostriatum up to $0.5 \mathrm{mV}$ in more lateral portions of the ectostriatum.

In the caudal ectostriatum, VEPs with large amplitudes and short latencies were recorded. At these locations the amplitude of the first peak of the negative wave was larger than that of the second peak. At the medial border, we recorded VEPs with small amplitudes and short latencies in caudal and rostral portions of the ectostriatum. The first and second negative peak were of almost equal amplitude. There is no clearly distinguishable positive peak at these locations (Fig. 1). In recordings at rostro-lateral ectostriatal coordinates, we obtained VEPs with larger amplitudes, long latency components, and a clearly distinguishable positive peak. At these locations the amplitude of the second peak of the negative wave was larger than the first peak (Fig. 1).

Reliable ipsilaterally evoked potentials could be recorded only in the lateral two thirds of the ectostriatal complex (Fig. 2). The ipsilateral flash evoked response is characterized by a slow negative wave with two slightly distinct peaks and, in some cases, a small positive wave. The maximal amplitude of about $0.1 \mathrm{mV}$ appears in the lateral ectostriatum. The 


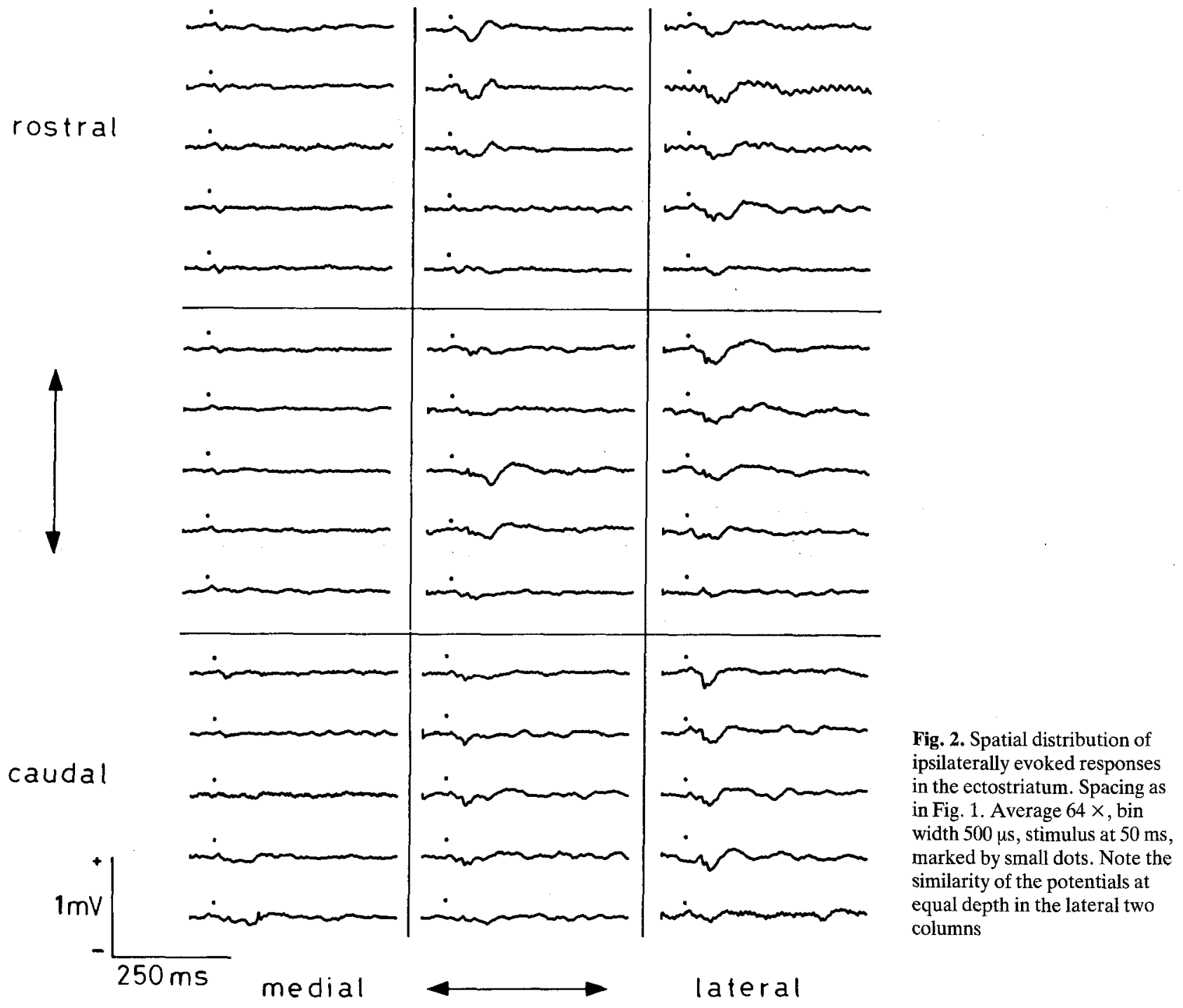

latencies of the negative peak range from 40 to $70 \mathrm{~ms}$. At the medial border of the ectostriatum we recorded small, fast positive-negative waves with short latencies of about $15 \mathrm{~ms}$ for the positive peak and $25 \mathrm{~ms}$ for the negative peak. As the latencies of these responses are smaller than those of the responses in the nucleus rotundus (around $30 \mathrm{~ms}$, unpublished results) they cannot be due to afferent connections from the nucleus rotundus. Possibly, these responses are due to a small bilateral projection from the nucleus dorsolateralis posterior (DLP) to the neostriatum intermedium (NI) as recently described by Gamlin and Cohen (1986).

\section{Current source-densities}

In two birds we compared the current source-density profile from a one dimensional current source- density analysis with that of a three dimensional current source-density analysis of a central track in the lateral ectostriatum (Fig. 3A, B). The striking feature in both current source-density depth profiles is a prominent current sink (a) from $2500 \mu \mathrm{m}$ to 3250 $\mu \mathrm{m}$ with a latency of about 50 to $65 \mathrm{~ms}$ (Fig. 3). This prominent early sink (a) sometimes could be differentiated in two distinguishable peaks. At the depth of 2500 and $2750 \mu \mathrm{m}$ it is preceded by a sharp early sink with a latency of about $30 \mathrm{~ms}$ (Fig. 3,f). Dorsal and ventral corresponding current sources can be detected. From $3500 \mu \mathrm{m}$ to $3750 \mu \mathrm{m}$ another early sharp current sink appears (Fig. 3,g). At a depth of $1750 \mu \mathrm{m}$, slightly above the ectostriatal core within the ectostriatal belt, a further current sink appears (Fig. 3,d). This dorsal sink (d) is separated from the dominant central sink (a) by a current source with corresponding latencies. The current sinks (a) and 
A

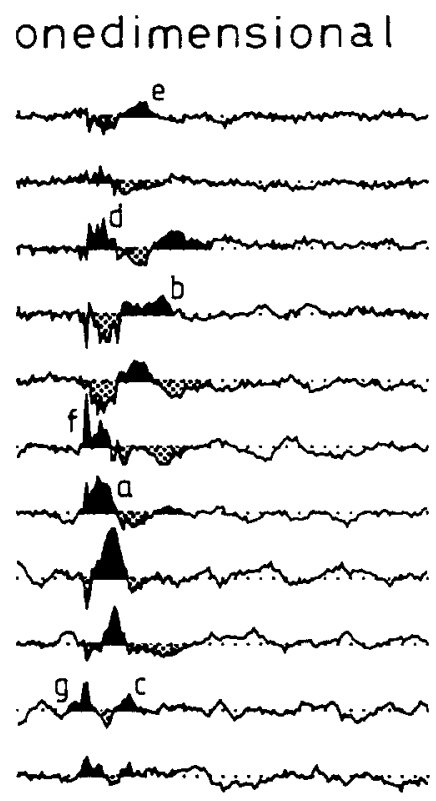

B

\section{threedimensional}

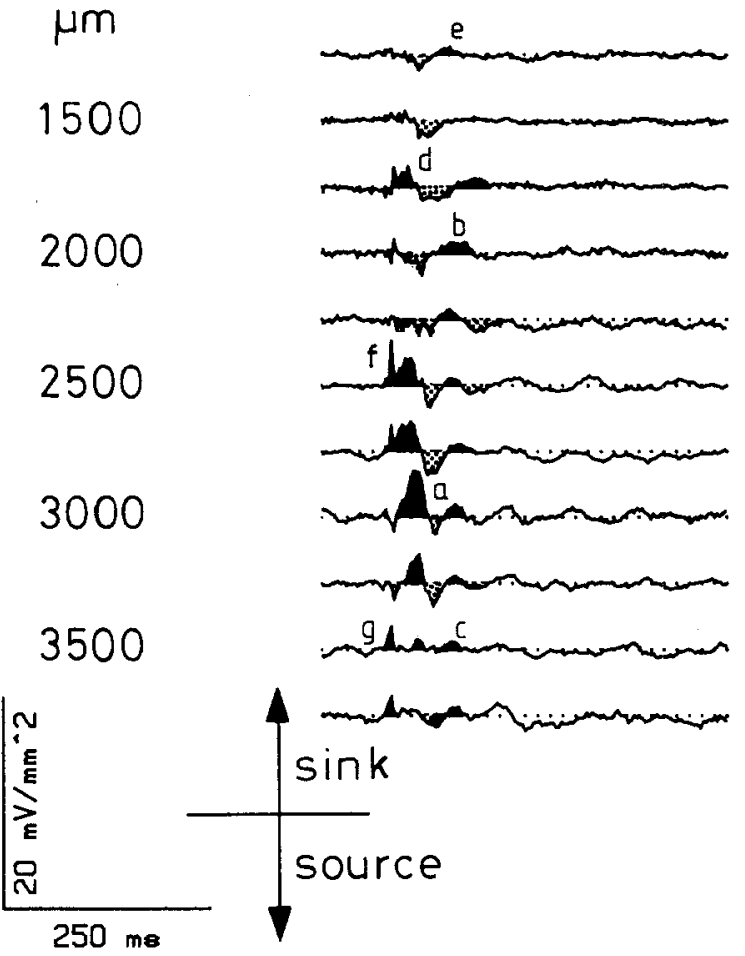

Fig. 3A, B. Comparison of a one dimensional current source-density calculation of a central track within the ectostriatum with a three dimensional current sourcedensity calculation from five tracks of equal spatial lattice for identical coordinates within the ectostriatum. Differentiation grid $500 \mu \mathrm{m}$, step width $250 \mu \mathrm{m}$ (d) are followed by temporally delayed current sources. A comparison of the current source-density profiles, revealed either by a one- or three-dimensional current source-density calculation, demonstrates that both profiles have predominantly corresponding sink-source distributions (compare Fig. 3A and $\mathrm{B}$ ).

The spatial distribution of contra- and ipsilaterally evoked VEPs shows that, at least in the lateral two thirds of the ectostriatal complex, the differences between neighbouring VEPs of equal depth are neglible compared to the differences of the VEPs of a single track at different depths (compare Figs. 1, 2 above). This, together with the correspondence of the sink-source distributions in the one and the three dimensional current source-density calculations (Fig. $3 \mathrm{~A}$ and $\mathrm{B}$ ), shows that a one dimensional current source-density analysis can be applied (e.g. Nicholson and Freeman 1975).

A comparison of the contralaterally evoked VEPs and the related current source densities demonstrates the higher spatial resolution and the focussing on distinct localized events in the current source-density profiles.

Figure 4 provides an example of a contralaterally evoked potential depth profile and its related current source-density profile together with a frontal section of the brain, which shows the recording sites within the ectostriatal core. In the current source-density profile calculated from these recordings, a first prominent current source can be detected at $1750 \mu \mathrm{m}$ slightly above the dorsal border of the ectostriatum. The latency of his source peak is about $50 \mathrm{~ms}$. This early source is followed by a small sink (b) with a latency of about $100 \mathrm{~ms}$. Between $2250 \mu \mathrm{m}$ and $2500 \mu \mathrm{m}$ (precisely at the dorsal border of the ectostriatum) the early source reverses into a current sink (a) with two small peaks, and the delayed sink (b) reverses into a source. At $2750 \mu \mathrm{m}$ the latency of the early sink (a) shifts from $50 \mathrm{~ms}$ to $65 \mathrm{~ms}$, while the latency of the delayed source is reduced to about $75 \mathrm{~ms}$. The delayed source reverses into a small sink (c) at $3250 \mu \mathrm{m}$. About $250 \mu \mathrm{m}$ deeper the early sink (a) reverses into a source. Thus, a source-sink-source pattern for the first part corresponds to a sink-sourcesink pattern of the second part.

With ipsilateral stimulation, a first small source with a latency of about $70 \mathrm{~ms}$ is detected at $2000 \mu \mathrm{m}$ (Fig. 5). It is followed by a small sink (b) with a latency of about $110 \mathrm{~ms}$. This coincides with the results of contralateral stimulation. At a depth of $2500 \mu \mathrm{m}$ the sinks and sources diminish. At $2750 \mu \mathrm{m}$ an early current sink (a) followed by a source is detected. The latencies of these sinks and sources are 


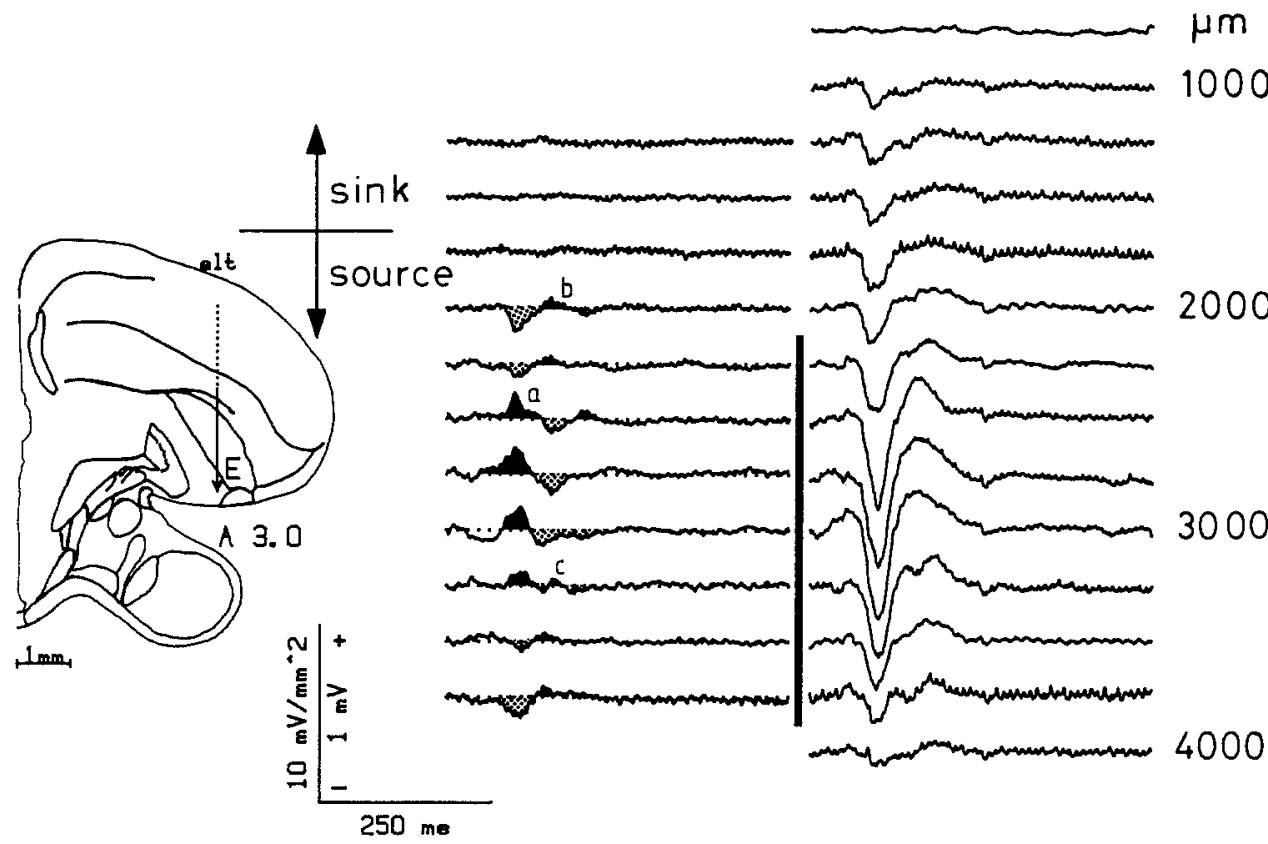

Fig. 4. Comparison of contralaterally evoked potentials and related current source densities in the ectostriatum. Left: Frontal section (Ant. 3) of the zebra finch brain with electrode track. Right: Evoked potential profile. Middle: Current source density profile. VEP: Average $64 \times$, bin width $500 \mu \mathrm{s}$, stimulus at $0 \mathrm{~ms}$. CSD: Differentiation grid $500 \mu \mathrm{m}$, step width $250 \mu \mathrm{m}$. The heavy bar (right) represents the solid part of the electrode track in the frontal brain section (left)

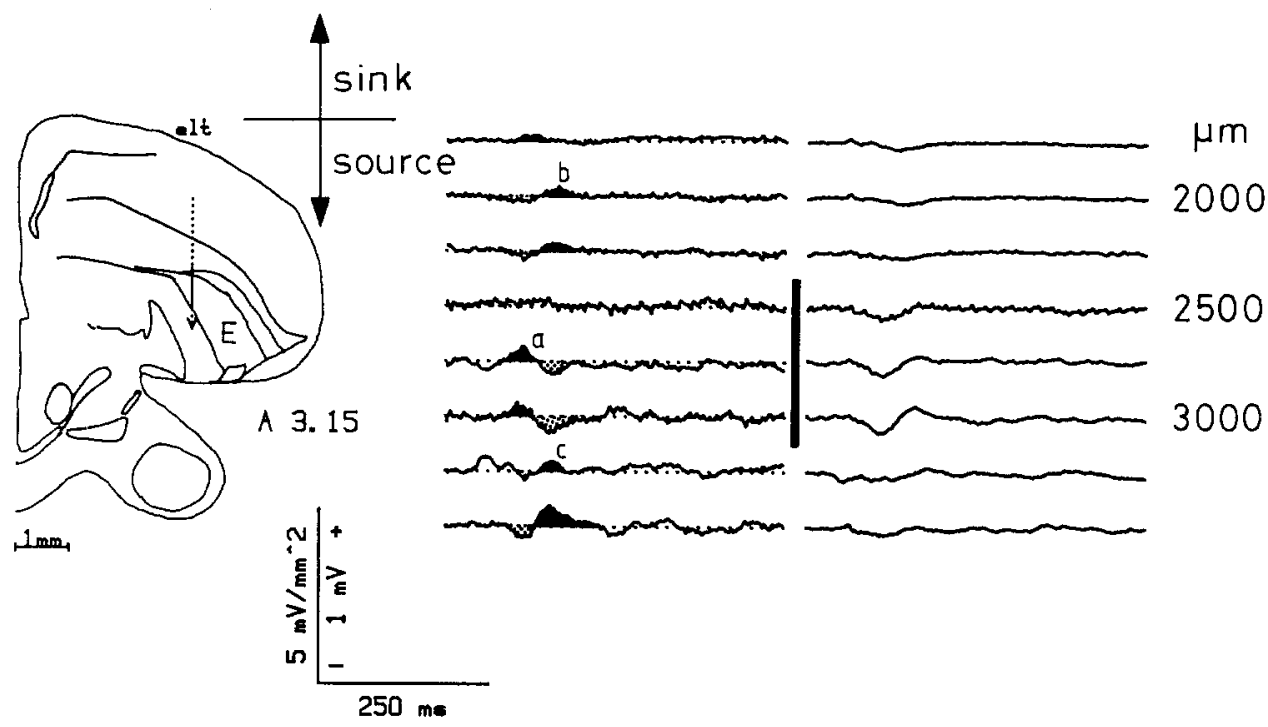

Fig. 5. Comparison of ipsilaterally evoked potentials and related current source-densities in the ectostriatum. Presentation as in Fig. 4

comparable to their reversals $500 \mu \mathrm{m}$ above. From $3000 \mu \mathrm{m}$ to $3250 \mu \mathrm{m}$ the sinks and sources reverse simultaneously. A comparison of both the contraand ipsilaterally evoked current source-density pattern shows that the sequence of sinks and sources is almost identical in both cases. However, the most prominent ipsilaterally evoked current sink (a) is more restricted to the ectostriatal core region than the contralaterally driven one (compare Figs. 4 and $5)$.

Comparing 20 current source-density depth profiles along electrode tracks at different coordinates, local differences from the source-sink-course (first part of the response) and sink-source-sink (second part of the response) pattern described above can be detected. First, from the medial to the lateral border of the ectostriatum a shift in depth from $3000 \mu \mathrm{m}$ (medial) to $3500 \mu \mathrm{m}$ (lateral) of the center of the prominent sink (a) and its related delayed source is observed (compare Figs. 6, 7). At the ventral border of the medial ectostriatum, the occurrence of an early source at a depth of $3750 \mu \mathrm{m}$ coincides with the reversal of the field potential (Fig. 6). This is not the case in the lateral ectostriatum. Second, whereas in the medial ectostriatum the current source-density depth profile for the first part is source-sink-source 

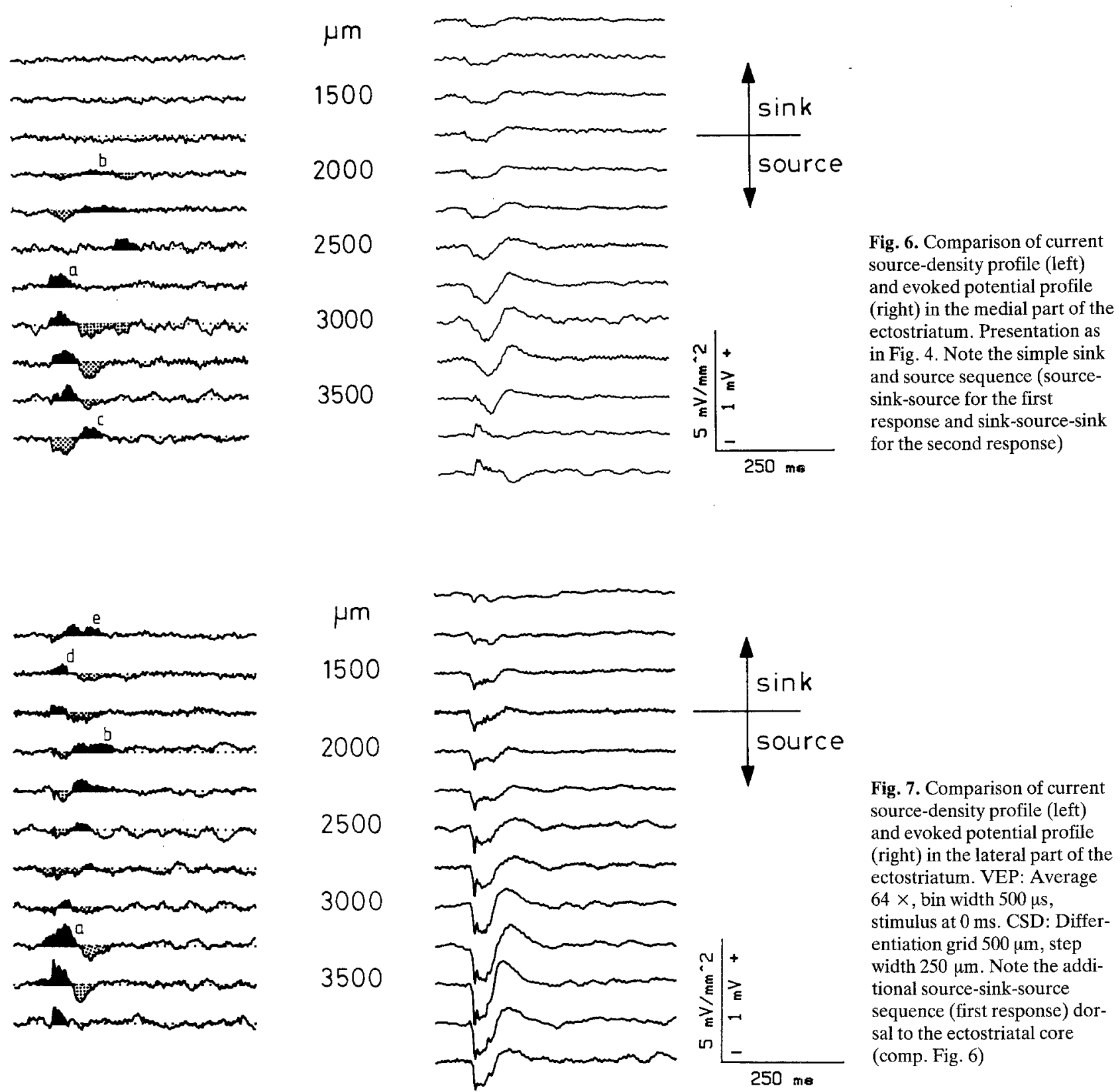

Fig. 7. Comparison of current source-density profile (left) and evoked potential profile (right) in the lateral part of the ectostriatum. VEP: Average $64 \times$, bin width $500 \mu s$, stimulus at $0 \mathrm{~ms}$. CSD: Differentiation grid $500 \mu \mathrm{m}$, step width $250 \mu \mathrm{m}$. Note the additional source-sink-source sequence (first response) dorsal to the ectostriatal core (comp. Fig. 6)

(see above), in the lateral ectostriatum the current source-density pattern is more differentiated along the depth axis (Fig. 7). In these electrode tracks an additional source-sink-source sequence can be detected above the ectostriatum: a dorsal sink (d) is separated from the central sink (a) by a common current source from 2000 to $3000 \mu \mathrm{m}$.

\section{Multiunit recordings}

To demonstrate that the evoked potentials are generated in the ectostriatal core and to obtain information about the question whether components of the evoked potentials are due to excitatory or inhibitory processes, we recorded flash evoked multiunit activity and evoked potentials at identical electrode coordinates. A comparison of these recordings demonstrates that the multiunit responses correspond well with the evoked potentials (Fig. 8A, B). The maximum spike rate in the contralateral multiunit activity (Fig. 8A) temporally coincides with the negative wave of the evoked potential curve. With the occurrence of the positive wave the spike rate decreases, possibly slightly below the level of spontaneous activity. This demonstrates that the first 

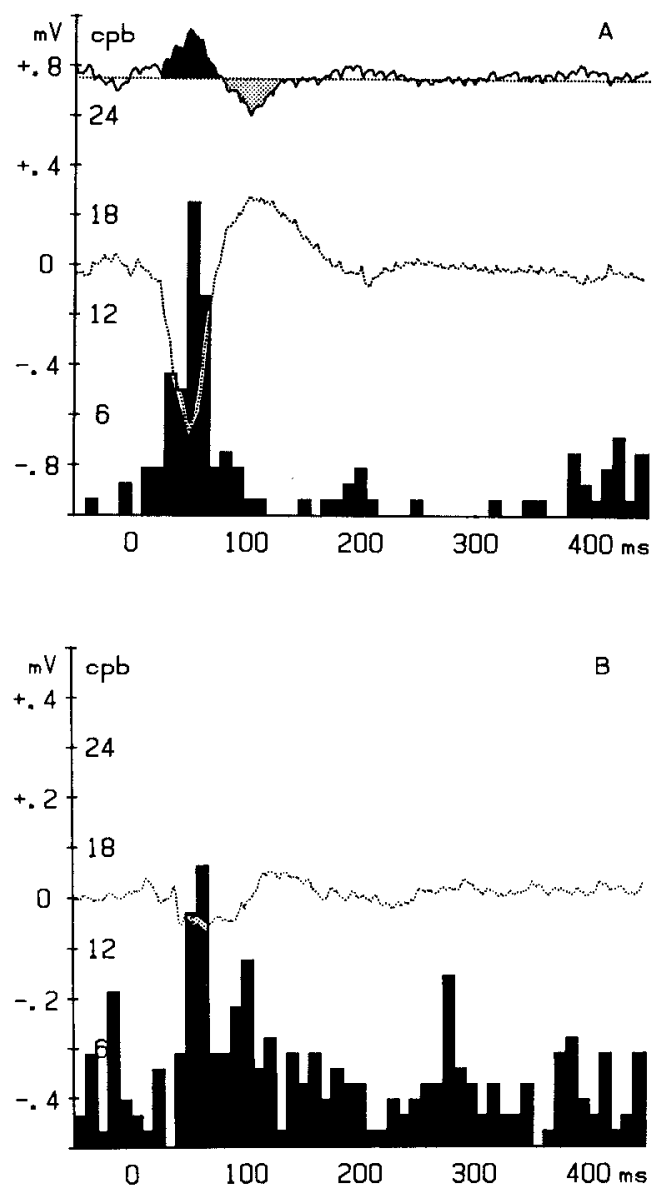

Fig. 8A,B. Visually evoked potentials, current source-densities, VEPs and multiunit activity at the same recording site. Stimulus at $0 \mathrm{~ms}$. Current source-densities: Differentiation grid $500 \mu \mathrm{m}$, ordinate scale in $\mathrm{V} / \mathrm{mm}^{2}$. VEPs: bin width $500 \mu$ s, average $64 \times$, ordinate scale in $\mathrm{mV}$, multiunits: bin width $10 \mathrm{~ms}$, average $16 \times$, ordinate scale in counts/bin (cpb). The distribution of multi-unit activity fits the VEP and current source density plot well

negative peak predominantly represents excitatory processes within the ectostriatum in the case of ipsilateral stimulation (Fig. 8B), both the multiunit and the evoked potential response are not as prominent as with contralateral stimulation, but show a time coincidence similar to the contralateral case.

\section{Discussion}

Until recently the higher stations of the tectofugal visual pathway of birds, the nucleus rotundus and the ectostriatum, have been thought to be involved solely in the processing of monocular visual information (Revzin and Karten 1966/67; Parker and Delius 1972). In contrast, Engelage and Bischof (1988) demonstrated a strong, presumably excitatory, ipsi- lateral influence on the telencephalic target of the tectofugal pathway, the ectostriatum, in normal and enucleated birds. This paper demonstrates that both contra- and ipsilateral stimulus responses can be detected throughout the entire ectostriatal complex. They both reach their maximum amplitudes in the lateral portion of the ectostriatum.

It also demonstrates that a current-source density analysis is applicable in a telencephalic structure in birds. Our results demonstrate that, in addition to the three dimensional form of current source-density analysis, the one dimensional current-source-density analysis can also be applied. This, in contrast to the VEPs, allows the exact localization of the generators of VEPs, the macroscopic current sinks and sources (Figs. 4, 5). Whereas the contralateral VEPs are detectable from about $1500 \mu \mathrm{m}$ above the ectostriatum, the prominent early sink (a) is clearly restricted to the ectostriatal core. This indicates that the ectostriatal core is really the source of the contralaterally evoked potentials and thus the location of the synaptic processes underlying the field potentials (Figs. 3, 4, 6, 7). The ipsilateral stimulus responses are due to a sink restricted to the ectostriatal core (Fig. 5).

Our data further indicate that synaptic processes within the ectostriactum are predominantly excitatory. This is demonstrated by the time coincidence of the central early sink (a) of the current sourcedensity analysis, the negative wave of the evoked potentials and the maximum spike rates in the multiunit recordings, respectively (Fig. 8). These results are in agreement with theoretical considerations concerning the physiological processes underlying the generation of evoked potentials which assume that predominantly dendritic synaptic activities contribute to the extracellularly recorded potentials (e.g. Llinas and Nicholson 1974; Mitzdorf 1985).

Several features of our results demonstrate that within the ectostriatum there is a higher degree of order than is expected from anatomical data. Within the ectostriatal core, no subdivision or lamination can be detected anatomically. However, several studies (Cohen and Karten 1974; Nixdorf and Bischof 1982) have demonstrated that the nucleus rotundus projects topographically into the ectostriatum, suggesting that there is at least a certain degree of topographical order in this area. From the distribution of macroscopic sinks and sources demonstrated above, it is likely that the ectostriatum is ordered functionally. Therefore, with physiological activation of the visual pathways, an orderly pattern of excitation is elicited in the ectostriatum which causes the macroscopic current sink and source distribution and, in turn, the related field potentials. 
The temporal sequence of sinks and sources in the current source-density depth profiles and the different peaks of the VEPs indicate that there are several steps of processing occurring within the ectostriatal core. As we normally used flash stimuli, a generation of the second negative peak by slower input fibers cannot be excluded. However, cooling and spreading depression experiments (Engelage and Bischof, in preparation) do not support this, but again suggest that there may be at least two successive steps of information processing within the ectostriatum (see below). Therefore, the small delayed sinks (b) and (c) (Figs. 4, 5) are probably the result of a successive bifurcating projection from the central sink (a).

Comparing the VEPs one can detect regional differences within the ectostriatum. As demonstrated in the results, the amplitude of the first peak in the VEP, probably representing the first step of processing within the ectrostriatum, reaches its maximum at the medioventral parts. Therefore, this area might be the location of the input from the Nucleus rotundus.

From the ventromedial areas of the ectostriatum information may be processed to rostro-lateral parts of the ectostriatum. In this region the second negative peak is higher than the first one, suggesting that a successive step of processing occurs here. This fits in well with experiments where we were able to demonstrate (Engelage and Bischof, in preparation) additional visual inputs coming from the visual wulst (via the hyperstriatum ventrale). We found that cooling and spreading depression in the visual wulst leads to a selective reduction of the second negative peak and the positive wave in the ectostriatal VEPs. A connection between the visual wulst and the ectostriatal core (via the hyperstriatum ventrale) has been described anatomically by Ritchie and Cohen (1977) and Watanabe et al. (1985).

The rostrolateral region is also the location of the additional source-sink-source sequence described above. From anterograde tracing experiments we have evidence that this region receives efferent fibers from the nucleus rotundus (Niemann and Bischof, in preparation), which are possibly collaterals from axons terminating in the medioventral part of the ectostriatum. Therefore, the additional source-sinksource sequence may be either due to an as yet undescribed projection of the tectofugal pathway or to a visual wulst-ectostriatal core interaction, or to both.

In summary, our results demonstrate by application of current source-density analysis and careful analysis of variations in the evoked potentials of different parts of the nucleus, that the ectostriatum is a brain area of higher order than previously believed. With further experiments it should be possible to examine this more precisely, and to create a basis for comparing this avian telencephalic structure with its mammalian homologue, the extrastriate cortex.

Acknowledgements. We are very grateful to Prof. Dr. Ulla Mitzdorf for valuable discussions on the CSD-method and very helpful comments on an earlier draft of the paper. Our thanks are also due to Mrs. Edda Geißler for her assistance in preparing the figures and to Dr. Nicky Clayton for improving the English. Supported by the Deutsche Forschungsgemeinschaft (Bi 245/3) and the Minister für Wissenschaft und Forschung des Landes Nordrhein-Westfalen.

\section{References}

Benowitz LJ, Karten HJ (1976) Organisation of the tectofugal visual pathway in the pigeon: a retrograde transport study. J Comp Neurol 167: 503-520

Bischof HJ (1981) A stereotaxic headholder for small birds. Brain Res Bull 7: 435-436

Cohen DH, Karten HJ (1974) The structural organisation of the avian brain: an overview. In: Goodman IJ, Schein MW (eds) Birds, brain and behaviour. Academic Press, New York, pp 29-73

Ebbesson SOE (1970) On the organisation of central visual pathways in vertebrates. Brain Behav Evol 3: 178-194

Engelage J, Bischof HJ (1988) Enucleation enhances ipsilateral flash evoked responses in the ectostriatum of the zebra finch (Taeniopygia guttata castanotis Gould). Exp Brain Res 70: 79-89

Freemann JA, Nicholson C (1975) Experimental optimization of current source-density technique for anuran cerebellum. J Neurophysiol 38: 369-382

Freemann JA, Stone J (1969) A technique for current sourcedensity analysis of field potentials and its application to the frog cerebellum. In: Llinas R (ed) Neurobiology of cerebellar evolution and development. Am Med Assoc, Chicago, pp 421-430

Gamlin PDR, Cohen DH (1986) A second ascending pathway from the optic tectum to the telencephalon in the pigeon (Columba livia). J Comp Neurol 250: 296-310

Granda AM, Yazulla S (1971) The spectral sensitivity of single units in the nucleus rotundus of the pigeon, Columbia livia. J Gen Physiol 57: 363-384

Hardy O, Leresche N, Jassik-Gerschenfeld D (1984) Postsynaptic potentials in neurons of the pigeon's optic tectum in response to afferent stimulation from the retina and other visual structures: an intracellular study. Brain Res 311: 65-74

Holden AL (1968a) The field potential profile during activation of the avian optic tectum. J Physiol (Lond) 194: 75-90

Holden AL (1968b) Types of unitary response and correlation with the field potential profile during activation of the avian optic tectum. J Physiol (Lond) 194: 91-106

Hunt SP, Künzle H (1976) Observations of the projections and intrinsic organisation of the pigeon optic tectum: an autoradiographic study based on anterograde and retrograde axonal and dendritic flow. J Comp Neurol 170: 153-172

Jassik-Gerschenfeld D, Guichard J (1972) Visual receptive fields of single cells in the pigeon's optic tectum. Brain Res 40: 303-317

Kimberly RP, Holden AL, Bamborough P (1971) Response characteristics of pigeon forebrain cells to visual stimulation. Vision Res 11: $475-478$ 
Llinas R, Nicholson C (1974) Analysis of field potentials in the central nervous system. In: Remond A (ed) Handbook of EEG and clinical neurophysiology, Vol 2. Electrical activity from the neuron to the EEG and EMG. Elsevier, Amsterdam, pp 62-92

Maxwell JH, Granda AM (1979) Receptive fields of movement sensitive cells in the pigeon thalamus. In: Maxwell $\mathrm{JH}$, Granda AM (eds) Neural mechanisms of behavior in the pigeon. Plenum Press, New York, pp 177-198

Mitzdorf U (1985) Current source-density method and application in cat cerebral cortex: investigation of evoked potentials and EEG phenomena. Physiol Rev 65: 37-100

Mitzdorf U (1987) Properties of the evoked potential generators: current source-density analysis of visually evoked potentials in the cat cortex. Int J Neurosci 33: 33-59

Mitzdorf U, Singer W (1977) Laminar segregation of afferents to lateral geniculate nucleus of the cat: an analysis of current source-density. J Neurophysiol 40: 1227-1244

Mitzdorf U, Singer W (1978) Prominent excitatory pathways in the cat visual cortex (A17 and A18): a current source-density analysis of electrically evoked potentials. Exp Brain Res 33: 371-394

Mori S (1973) Analysis of field response in optic tectum of the pigeon. Brain Res 54: 193-206

Müller-Preuss P, Mitzdorf U (1984) Functional anatomy of the inferior colliculus and the auditory cortex: current source density analyses of click-evoked potentials. Hearing Res 16 : 133-142

Nicholson C, Freeman JA (1975) Theory of current source-density analysis and determination of conductivity tensor for anuran cerebellum. J Neurophysiol 38: 356-368

Nixdorf BN, Bischof HJ (1982) Afferent connections of the ectostriatum and visual wulst in the zebra finch (Taeniopygia guttata castanotis Gould): a HRP study. Brain Res 248: 9-17
Parker DM, Delius JD (1972) Visual evoked potentials in the forebrain of the pigeon. Exp Brain Res 14: 198-209

Pettigrew JD (1977) Comparison of the retinotopic organization of the visual wulst in nocturnal and diurnal raptors, with a note on the evolution of frontal vision. In: Cool SJ, Smith III EL (eds) Frontiers in visual science. Springer, Berlin Heidelberg New York, pp 328-333

Revzin AM (1970) Some characteristics of wide field units in the brain of the pigeon. Brain Behav Evol 3: 195-204

Revzin AM, Karten HJ (1966/67) Rostral projections of the optic tectum and the nucleus rotundus in the pigeon. Brain Res 3: 264-276

Ritchie TC, Cohen DH (1977) The avian tectofugal visual pathway: projections of its telencephalic target, the ectostriatal complex. Soc Neurosci Abstr 3: 94

Robert F, Cuenod M (1969a) Electrophysiology of the intertectal commissures in the pigeon. I. Analysis of the pathways. Exp Brain Res 9: 116-121

Robert F, Cuenod M (1969b) Electrophysiology of the intertectal commissures in the pigeon. II. Inhibitory interaction. Exp Brain Res 9: 123-136

Stone J, Freemann JA (1971) Synaptic organization of the pigeon's optic tectum: a Golgi and current source-density analysis. Brain Res 27: 203-221

Yazulla S, Granda AM (1973) Opponent colour units in the thalamus of the pigeon (Columbia livia). Vision Res 13: $1555-1563$

Watanabe M, Ito H, Ikushima M (1985) Cytoarchitecture and ultrastructure of the avian ectostriatum: afferent terminals from the dorsal telencephalon and some nuclei in the thalamus. J Comp Neurol 236: 241-257

Received January 4, 1988 / Accepted September 6, 1988 